\title{
Editorial: Marine Microbiome and Biogeochemical Cycles in Marine Productive Areas
}

\author{
Alejandro A. Murillo ${ }^{1 *}$, Verónica Molina ${ }^{2}$, Julio Salcedo-Castro ${ }^{2}$ and Chris Harrod ${ }^{3,4}$ \\ ${ }^{1}$ Structural and Computational Biology, European Molecular Biology Laboratory, Heidelberg, Germany, ${ }^{2}$ Departamento de \\ Biología, Universidad de Playa Ancha, Valparaíso, Chile, ${ }^{3}$ Instituto de Ciencias Naturales Alexander von Humboldt, \\ Universidad de Antofagasta, Antofagasta, Chile, ${ }^{4}$ Núcleo Milenio INVASAL, Concepción, Chile
}

Keywords: coastal areas, upwelling systems, carbon cycle, nitrogen cycle, microbial oceanography, high nutrients, microbial diversity, coastal ecosystems

\section{Editorial on the Research Topic}

\section{Marine Microbiome and Biogeochemical Cycles in Marine Productive Areas}

The global ocean covers more than $70 \%$ of the Earth's surface and is remarkably heterogeneous. Marine productive areas, and coastal ecosystems comprise a minor fraction of the ocean in terms of surface area, yet have an enormous impact on global biogeochemical cycles carried out by microbial communities, which represent $90 \%$ of the ocean's biomass (Alexander et al., 2011). These marine productive areas also vary considerably in terms of primary and secondary production, and are classified as highly productive or class I (>300 $\mathrm{gC} \mathrm{m}^{-2} \mathrm{yr}^{-1}$ ), moderately productive or class II (150-300 $\left.\mathrm{gC} \mathrm{m}^{-2} \mathrm{yr}^{-1}\right)$, to low productive or class III $\left(<150 \mathrm{gC} \mathrm{m}^{-2} \mathrm{yr}^{-1}\right)$. Work to date has largely focused on cycling of carbon and macronutrients such as nitrogen, phosphorus,

\section{OPEN ACCESS}

Edited and reviewed by:

François G. Schmitt,

UMR8187 Laboratoire d'Océanologie et de Géosciences (LOG), France

*Correspondence:

Alejandro A. Murillo alejandro.murillo@embl.de

Specialty section: This article was submitted to Coastal Ocean Processes, a section of the journal Frontiers in Marine Science

Received: 16 July 2019 Accepted: 09 October 2019 Published: 22 October 2019

Citation: Murillo AA, Molina V, Salcedo-Castro J and Harrod C (2019) Editorial: Marine

Microbiome and Biogeochemical Cycles in Marine Productive Areas.

Front. Mar. Sci. 6:657. doi: 10.3389/fmars.2019.00657 and silicate: other important elements such as sulfur or trace elements have been less studied, reflecting associated technical and logistical issues. Increasingly, these marine areas, and the taxa that form their ecosystems, are subject to significant anthropogenic pressure, impacting marine life and recycling of energy and nutrients (Galton, 1884; Hasler, 1969; Jickells et al., 2017). A key example is that of cultural eutrophication, where agricultural run-off leads to nitrogen and phosphorus enrichment of coastal ecosystems, greatly increasing productivity resulting in algal blooms, deoxygenation of the water column and seabed, and increased greenhouse gas emissions (Bouwman et al., 2005), with direct local and global impacts on nitrogen and carbon cycles. However, the runoff of organic matter from the mainland to coastal ecosystems is just one of a series of pressing threats stressing microbial communities due to global change. Climate change has also resulted in changes in the cryosphere, as glaciers and permafrost melt, resulting in intensified marine stratification, while shifts of the redox-state in different biomes are rapidly reshaping microbial assemblages at an unprecedented rate (Altieri and Gedan, 2015; Breitburg et al., 2018; Cavicchioli et al., 2019; Hutchins et al., 2019).

Global change is, therefore, affecting key processes including primary productivity, $\mathrm{CO}_{2}$ and $\mathrm{N}_{2}$ fixation, organic matter respiration/remineralization, and the sinking and burial deposition of fixed $\mathrm{CO}_{2}$ (Hutchins et al., 2019). In addition to this, oceans are experiencing an acidification process, with a change of $\sim 0.1 \mathrm{pH}$ units between the pre-industrial period and today, affecting carbonate/bicarbonate buffer chemistry. In turn, acidification has been reported to impact planktonic communities, principally through effects on calcifying taxa (Stillman and Paganini, 2015). There is also evidence for shifts in the production of key intermediary volatile products, some of which have marked greenhouse effects (e.g., $\mathrm{N}_{2} \mathrm{O}$ and $\mathrm{CH}_{4}$, reviewed by Breitburg et al., 2018), due to the increase in global temperature, ocean stratification and deoxygenation, driving 
as much as $\sim 25-50 \%$ of nitrogen loss from the ocean to the atmosphere in the so-called oxygen minimum zones (Bertagnolli and Stewart, 2018) or anoxic marine zones (Ulloa et al., 2012), driven by microbial processes. Other products, that are typically toxic for the marine nekton, including reduced sulfur species such as $\mathrm{H}_{2} \mathrm{~S}$, have a negative impact for marine resources like fisheries and coastal aquaculture. While global change has accelerated, there has been a parallel increase in awareness of the complexity of marine ecosystems, and especially the fundamental role of microbes as drivers of ecosystem functioning (Cavicchioli et al., 2019). At the same time, calls have intensified for the need for representative ecosystem-based models that can guide effective management of marine ecosystems. An example of this is the call made by the United Nations, proclaiming the Decade of Oceans Science for Sustainable Development 2012-2030 (https:// en.unesco.org/ocean-decade).

This Research Topic is focused on studies characterizing the complexity of interactions seen in microbial communities, and their response to environmental variation across a comprehensive range of marine habitats. These extend from coral reefs stressors and microbialization (Meirelles et al.), through to coastal habitats including glaciers in a Norwegian archipelago (Garcia-Lopez et al.), to the deep-sea floor and the spatial heterogeneity of a submarine canyon system (Román et al.). Other authors examined the picoeukaryotic community dynamics in the Northwestern Pacific Ocean (Wang et al.), the influence of river discharges (Masotti et al.) and temporal variability of net primary production (Testa et al.) both in an upwelling system of the Eastern Subtropical South Pacific Ocean. The role of microbial communities in the carbon cycle is at the core of our Research Topic, including the fate of dissolved organic carbon in upwelling systems (Bif et al.), the utilization of onecarbon and methylated compounds in the coastal environment (Dinasquet et al.) and dissolved organic matter derived from permafrost thaw in Arctic fjords, influencing the microbial communities (Müller et al.). This diversity of environments and microbial processes provides a small glimpse of the multiple roles that microbial communities play in marine ecosystems. Other important aspects include the potential for

\section{REFERENCES}

Alexander, V., Miloslavich, P., and Yarincik, K. (2011). The Census of Marine Life-evolution of worldwide marine biodiversity research. Mar. Biodivers. 41, 545-554. doi: 10.1007/s12526-0110084-1

Altieri, A. H., and Gedan, K. B. (2015). Climate change and dead zones. Glob. Chang. Biol. 21, 1395-1406. doi: 10.1111/gcb.12754

Bertagnolli, A. D., and Stewart, F. J. (2018). Microbial niches in marine oxygen minimum zones. Nat. Rev. Microbiol. 16, 723-729. doi: 10.1038/s41579-0180087-z

Bouwman, A. F., Van Drecht, G., Knoop, J. M., Beusen, A. H. W., and Meinardi, C. R. (2005). Exploring changes in river nitrogen export to the world's oceans. Global Biogeochem. Cycles 19:1002. doi: 10.1029/2004G B002314 biotechnological applications regarding the discovery of new bio-active compounds in a mangrove soil community (Chen et al.), the first sponge microbiome from the Persian Gulf (Najafi et al.) and the microbiome of the ecological engineer giant kelp Macrocystis pyrifera, including the utilization of alginate (Lin et al.).

As we face a climate crisis and other pressing threats to human life, such as the rise of antibiotic resistance (MacFadden et al., 2018) and the expansion of oxygendeficient zones affecting fishing resources (Roman et al., 2019), marine microbial communities (including the microbiome of marine organisms) offer a plethora of potential sustainable and environmentally-friendly practices to reduce our impact on the environment and improve human lives. This includes the identification of novel bioactive compounds, development of green-blue energy, effective and efficient sewage treatments, and the mitigation of $\mathrm{CO}_{2}$ production, as carbon burial, and other greenhouse gases. By increasing our understanding of the functioning of those natural processes that allow our planet to auto-regulate and respond to perturbations, we can apply such knowledge to surmount current and imminent environmental problems. Life is thought to have originated in the ocean and since then, to the actual state of the biosphere, marine habitats have been the support to an astonishing diversity of life forms and metabolic pathways. As such, increasing our understanding on how the largest biome on Earth functions is possibly the most important enterprise of the upcoming decades and can provide answers and solutions for many of the current challenges that humankind faces.

\section{AUTHOR CONTRIBUTIONS}

All authors listed have made a substantial, direct and intellectual contribution to the work, and approved it for publication.

\section{ACKNOWLEDGMENTS}

We thank all the contributors to this Research Topic.

Breitburg, D., Levin, L. A., Oschlies, A., Grégoire, M., Chavez, F. P., Conley, D. J., et al. (2018). Declining oxygen in the global ocean and coastal waters. Science 359:eaam7240. doi: 10.1126/science.aa $\mathrm{m} 7240$

Cavicchioli, R., Ripple, W. J., Timmis, K. N., Azam, F., Bakken, L. R., Baylis, M., et al. (2019). Scientists' warning to humanity: microorganisms and climate change. Nat. Rev. Microbiol. 17, 569-586. doi: 10.1038/s41579-0190222-5

Galton, D. (1884). 10th Meeting: report of the royal commission on metropolitan sewage. J. Soc. Arts 33, 290.

Hasler, A. D. (1969). Cultural eutrophication is reversible. Bioscience 19, 425-431. doi: $10.2307 / 1294478$

Hutchins, D. A., Jansson, J. K., Remais, J. V., Rich, V. I., Singh, B. K., and Trivedi, P. (2019). Climate change microbiology - problems and perspectives. Nat. Rev. Microbiol. 17, 391-396. doi: 10.1038/s41579-019-0178-5. 
Jickells, T. D., Buitenhuis, E., Altieri, K., Baker, A. R., Capone, D., Duce, R. A., et al. (2017). A reevaluation of the magnitude and impacts of anthropogenic atmospheric nitrogen inputs on the ocean. Global Biogeochem. Cycles 31, 289-305. doi: 10.1002/2016GB005586

MacFadden, D. R., McGough, S. F., Fisman, D., Santillana, M., and Brownstein, J. S. (2018). Antibiotic resistance increases with local temperature. Nat. Clim. Change 8, 510-514. doi: 10.1038/s41558-0180161-6

Roman, M. R., Brandt, S. B., Houde, E. D., and Pierson, J. J. (2019). Interactive effects of hypoxia and temperature on coastal pelagic zooplankton and fish. Front. Mar. Sci. 6:139. doi: 10.3389/fmars.2019. 00139

Stillman, J. H., and Paganini, A. W. (2015). Biochemical adaptation to ocean acidification. J. Exp. Biol. 218, 1946-1955. doi: 10.1242/jeb. 115584
Ulloa, O., Canfield, D. E., DeLong, E. F., Letelier, R. M., and Stewart, F. J. (2012). Microbial oceanography of anoxic oxygen minimum zones. Proc. Natl. Acad. Sci. U.S.A. 109, 15996-16003. doi: 10.1073/pnas.1205009109

Conflict of Interest: The authors declare that the research was conducted in the absence of any commercial or financial relationships that could be construed as a potential conflict of interest.

Copyright (๑ 2019 Murillo, Molina, Salcedo-Castro and Harrod. This is an openaccess article distributed under the terms of the Creative Commons Attribution License (CC BY). The use, distribution or reproduction in other forums is permitted, provided the original author $(s)$ and the copyright owner(s) are credited and that the original publication in this journal is cited, in accordance with accepted academic practice. No use, distribution or reproduction is permitted which does not comply with these terms. 